\title{
The role of distinct BRD4 isoforms and their contribution to high-grade serous ovarian carcinoma pathogenesis
}

\author{
Ana Luiza Drumond-Bock* (1) and Magdalena Bieniasz(1)
}

\begin{abstract}
High-grade serous ovarian carcinoma (HGSOC) is the most aggressive type of ovarian cancer, often diagnosed at advanced stages. Molecularly, HGSOC shows high degree of genomic instability associated with large number of genetic alterations. BRD4 is the 4th most amplified gene in HGSOC, which correlates with poor patients' prognosis. BRD4 is constitutively expressed and generates two proteins, BRD4 long (BRD4-L) and BRD4 short (BRD4-S). Both isoforms contain bromodomains that bind to lysine-acetylated histones. Amongst other functions, BRD4 participates in chromatin organization, acetylation of histones, transcriptional control and DNA damage repair. In cancer patients with amplified BRD4, the increased activity of BRD4 is associated with higher expression of oncogenes, such as MYC, NOTCH3 and NRG1. BRD4-driven oncogenes promote increased tumor cells proliferation, genetic instability, epithelialmesenchymal transition, metastasis and chemoresistance. Ablation of BRD4 activity can be successfully achieved with bromodomain inhibitors (BETi) and degraders, and it has been applied in pre-clinical and clinical settings. Inhibition of BRD4 function has an effective anti-cancer effect, reducing tumor growth whether ablated by single agents or in combination with other drugs. When combined with standard chemotherapy, BETi are capable of sensitizing highly resistant ovarian cancer cell lines to platinum drugs. Despite the evidence that BRD4 amplification in ovarian cancer contributes to poor patient prognosis, little is known about the specific mechanisms by which BRD4 drives tumor progression. In addition, newly emerging data revealed that BRD4 isoforms exhibit contradicting functions in cancer. Therefore, it is paramount to expand studies elucidating distinct roles of BRD4-L and BRD4-S in HGSOC, which has important implications on development of therapeutic approaches targeting BRD4.
\end{abstract}

Keywords: BRD4, High-grade serous ovarian carcinoma, Gene amplification, BET inhibitors

\section{Background}

Ovarian carcinoma remains one of the deadliest malignancies in the United States, rating amongst the top five causes of death for women between 40 and 79 years old [1]. High-grade serous ovarian carcinoma (HGSOC) is the most prevalent and most aggressive histotype of ovarian cancer. Clinical data revealed that in the majority of patients, HGSOC was detected at advanced stages,

*Correspondence: AnaLuiza-Bock@omrforg Aging and Metabolism Research Program, Oklahoma Medical Research Foundation, Oklahoma City, OK 73104, USA estimating that more than $75 \%$ of the cases were diagnosed at stage III and IV [2]. The advanced tumor stage and the poor survival rate of ovarian carcinoma patients $[2,3]$ reinforce the need for more rigorous studies to improve the knowledge surrounding HGSOC tumor initiation and progression, as well as response to treatments.

The analysis of genomic landscape of HGSOC tumors $[4,5]$ identified prevalent alterations of TP53 gene, which is mutated in $96 \%$ of the patients. Another commonly observed genetic alteration is the loss of function of $B R C A 1$ and $B R C A 2$, either by mutation or by epigenetic silencing $[4,6]$. Loss of $B R C A 1 / 2$ leads to a original author(s) and the source, provide a link to the Creative Commons licence, and indicate if changes were made. The images or other third party material in this article are included in the article's Creative Commons licence, unless indicated otherwise in a credit line to the material. If material is not included in the article's Creative Commons licence and your intended use is not permitted by statutory regulation or exceeds the permitted use, you will need to obtain permission directly from the copyright holder. To view a copy of this licence, visit http://creativecommons.org/licenses/by/4.0/. The Creative Commons Public Domain Dedication waiver (http://creativeco mmons.org/publicdomain/zero/1.0/) applies to the data made available in this article, unless otherwise stated in a credit line to the data. 
deficient DNA repair and impaired homologous recombination (HR) [7] resulting in chromosomal instability [8]. HR is found to be defective in approximately $50 \%$ of the patients with HGSOC [4]. Approximately $13 \%$ of the $B R C A 1 / 2$ mutations can be attributed to inherited germline mutations $[4,6]$. However, there is a subgroup of patients in which HGSOC-associated genomic instability occurs in a non-hereditary manner, and is often characterized by frequent genetic alterations (including genes amplification and deletion) in somatic cells [4, 9]. Data generated by The Cancer Genome Atlas [4] reported that the top three most common focal amplifications found in HGSOC patients encoded the genes MECOM, CCNE1 and $M Y C$. The BRD4 gene represents the 4th most frequent somatic amplification in HGSOC [10], and its amplification is present in $18 \%$ of ovarian cancer patients $[4,10]$. The majority of BRD4-amplified tumors shows no $B R C A 1 / 2$ alterations [11] suggesting that genomic instability in those tumors could be driven by mechanisms other than DNA repair deficiency.

BRD4 belongs to the Bromodomain and Extra-Terminal domain family of proteins (BET) [12, 13], which are known for their ability to bind to acetylated histones [14]. As an important transcriptional co-activator, BRD4 participates in several relevant processes in cancer, including DNA damage repair $[15,16]$ and cellular stress response $[17,18]$. BRD4 amplification [10, 11, 19] and/or overexpression [20] in ovarian tumors is often associated with a poor disease outcome $[10,11,19-21]$. The substantial impact of $B R D 4$ aberrations on patients' prognosis makes BRD4 an excellent candidate for basic and pre-clinical research to facilitate the development of targeted therapies. In fact, several Phase I and II clinical trials have been initiated using BET inhibitors (BETi), alone or in combination with other drugs [22-27].

The BRD4 gene encodes two main isoforms, BRD4 long (BRD4-L) and BRD4 short (BRD4-S) (Fig. 1) [10, 28, 29]. Studies indicate that a fine control of the BRD4 mRNA splicing is required to generate a balanced, constant ratio of both isoforms ensuring the homeostatic work of the protein [28] (Fig. 2). Recent data demonstrated that disruption of the balance between the two BRD4 isoforms may occur in certain diseases leading to significant biological consequences [10, 30, 31]. Further, BRD4-L and BRD4-S show different interaction patterns and distinct dynamics of transcriptional activity indicating divergent roles of these isoforms in the regulation of target genes. For instance, when overexpressed [28, 32], BRD4 isoforms tend to have opposing functions in breast cancer, BRD4-S exhibits oncogenic properties, while BRD4$\mathrm{L}$ has a tumor suppressor role [30, 31]. These findings emphasize the need to depict the biological role of individual BRD4 isoforms in respective diseases, including ovarian cancer, to facilitate development of therapeutic interventions.

Hence, the purpose of this article is to deliver a brief overview of the functions of both BRD4 isoforms in healthy and cancerous cells. We provide an insight into the potential mechanism of how BRD4 dysfunction contributes to the development and progression of HGSOC. Further, we discuss the therapeutic strategies to inhibit this oncogene, which may lead to the development of new treatment strategies for patients with ovarian cancer.

\section{The role of distinct BRD4 isoforms Structure and function of BRD4 isoforms}

BRD4 isoforms belong to the BET protein family $[12,13]$ characterized by the presence of two tandem bromodomains (BD) and one extra terminal domain (ETD) [12] (Fig. 1). BRD4 was first described in the early 2000's [13] as a murine protein and referred to as mitotic chromosome-associated protein (MCAP). At that time, scientists described MCAP as a protein that is distributed uniformly in the nucleus during interphase of the cell cycle, which becomes associated with condensed chromosomes throughout mitosis $[33,34]$. The fact that BRD4 (then

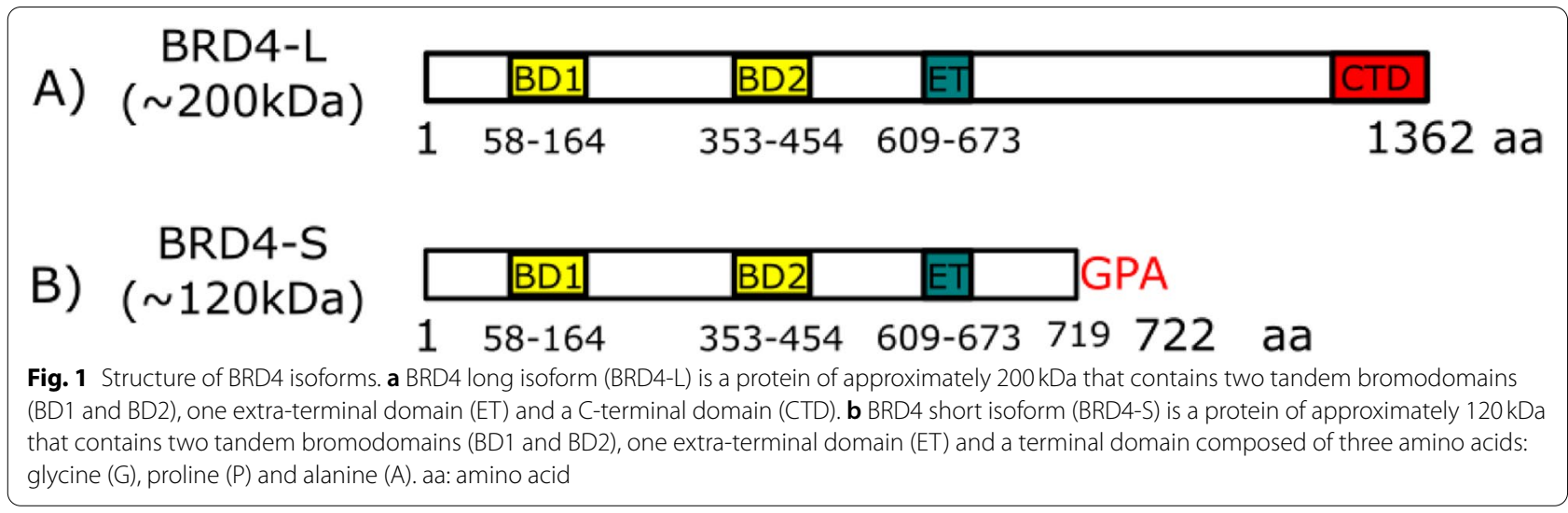




\section{A)BRD4 in healthy cells}

Homeostatic balance
of BRD4 isoforms

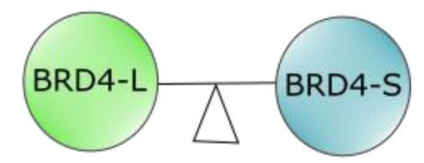

*Chromatin organization

*Transcriptional activation

*Cell cycle checkpoints control

*DNA damage repair

*Stress response

\section{B)BRD4 Amplification in HGSOC}

\section{Increased activity \\ of BRD4-L:}

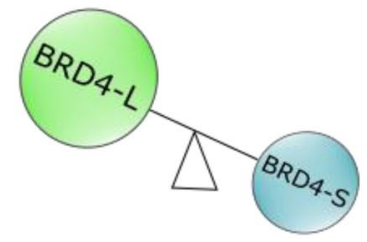

*Chromatin less condensed

*Increased transcription of oncogenes

*Promotion of NHEJ

\section{Increased activity of BRD4-S:}

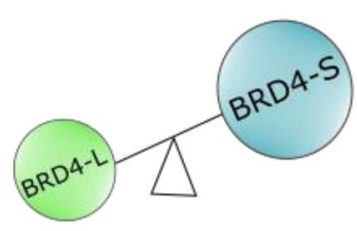

*Chromatin more compact

*Increased DNA damage

Fig. 2 The distinct roles of BRD4 isoforms. a Healthy cells show balanced levels of BRD4-L and BRD4-S isoforms performing their respective homeostatic functions. $\mathbf{b}$ In patients with High-Grade Serous Ovarian Carcinoma (HGSOC), the amplification of BRD4 results in different levels of BRD4 isoforms implicated in distinct tumor promoting functions

MCAP) remained associated with chromatin in the cell cycle phase in which most proteins are released into the cytoplasm has lead these authors to propose that BRD4 plays an important role in the chromatin dynamic during mitosis [13]. Further studies have defined BRD4 isoforms as epigenetic markers (Fig. 3) that bind to acetylated core histones and are transmitted to daughter cells, establishing the histone code across cell division [35-37].

Thus far, the majority of the studies investigating the function of BRD4 focused on its long isoform (Table 1). BRD4-L contains two tandem bromodomains, one extraterminal domain, and a C-terminal domain (Fig. 1A). While BRD4 bromodomains and the extra-terminal domain are highly conserved amongst BET proteins, the C-terminal domain is highly unique conferring BRD4$\mathrm{L}$ a distinct transcriptional co-activator function [38]. Although BRD4-L is more active and more frequently expressed isoform, BRD4-S appears to be highly relevant as well. Studies revealed that BRD4-S is the predominant isoform binding to modified histones [38] with a stronger binding affinity to the chromatin than BRD4-L [39]. BRD4-S has the same N-terminal segment as BRD4-L, but lacks the C-terminal domain (Fig. 1B). Additionally, BRD4-S contains three unique $\mathrm{C}$-terminal residues (GPA), not present in BRD4-L [39, 40]. To date, no specific function has been attributed to the GPA residues of BRD4-S.

\section{Chromatin organization and HAT function of BRD4 isoforms}

The bromodomains of the BET proteins are structures capable of recognizing and binding to lysine-acetylated histones [38, 48, 49]. BRD4 isoforms bind to the chromatin when recruited and detach when not needed, working as an "on and off" switch [37]. BRD4 predominantly binds to histone $\mathrm{H} 4$ acetylated in lysine 5,8 and 12 (H4K5Ac/H4K8Ac/H4K12Ac) [36, 37, 50]; BRD4 isoforms can also associate with histone $\mathrm{H} 3$, acetylated in lysine 14 (H3K14Ac) with a somewhat lower affinity [37]. 


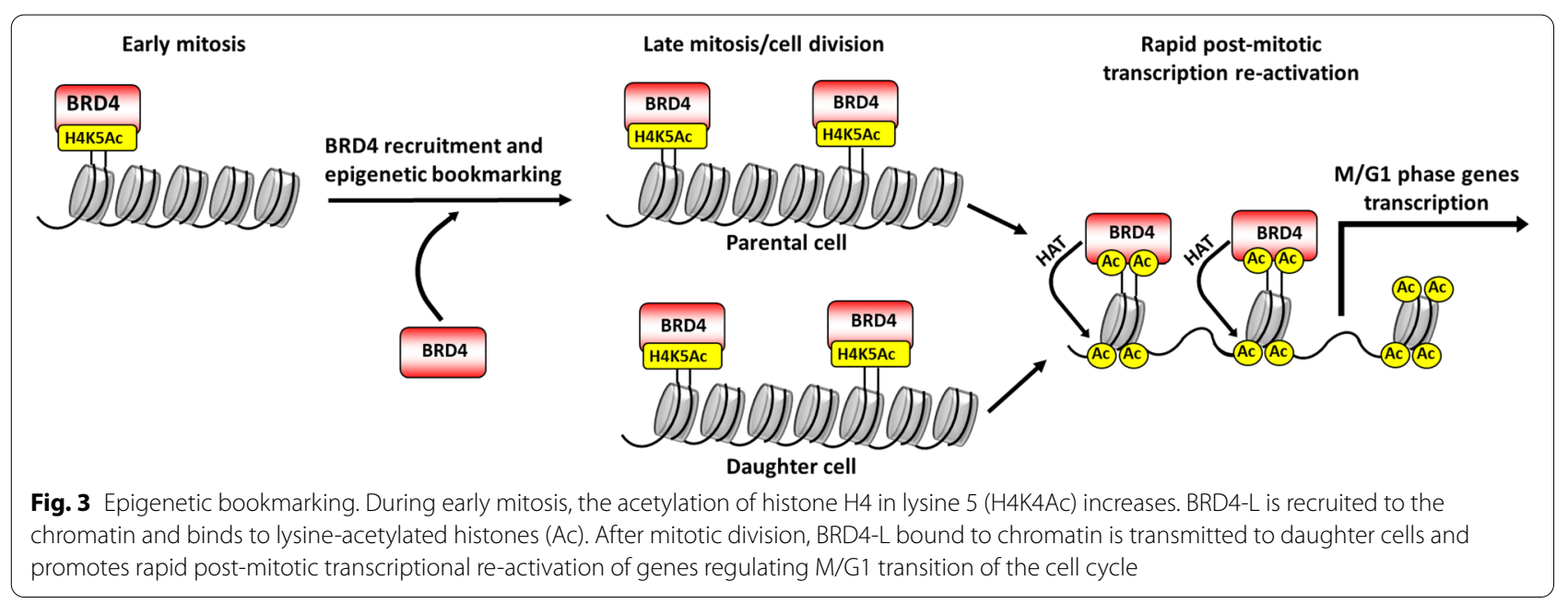

Table 1 Isoform-specific functions of BRD4

\begin{tabular}{|c|c|c|}
\hline Isoform & Function & Ref. \\
\hline & Serves as transcriptional co-activator & {$[41,42]$} \\
\hline \multirow[t]{10}{*}{ BRD4 isoform long (BRD4-L) } & Promotes RNA transcription via RNA Polymerase II pause-release & {$[41-43]$} \\
\hline & Has intrinsic histone acetyltransferase activity & {$[44]$} \\
\hline & Maintains higher-order chromatin structure & {$[38]$} \\
\hline & Induces expression of genes involved in the DNA repair pathway NHEJ & {$[15,16]$} \\
\hline & Provides structural support for NHEJ protein complex & {$[15,16,45]$} \\
\hline & Regulates transcription of primary response genes & {$[17]$} \\
\hline & Regulates transcription of antioxidant genes via interaction with NRF2 & {$[18]$} \\
\hline & Indirectly induces generation of ROS via KEAP1-NRF2 pathway & {$[46]$} \\
\hline & Has transformative potential in epithelial ovarian cells & {$[10]$} \\
\hline & Predominantly binds to lysine-acetylated histones & {$[38]$} \\
\hline \multirow[t]{5}{*}{ BRD4 isoform short (BRD4-S) } & Promotes chromatin compaction & {$[38]$} \\
\hline & Incorporates BRD4 condensation into the chromatin & {$[39]$} \\
\hline & Sustains transcription of proliferative genes in cancer cells via phase separation & [39] \\
\hline & Inhibits DNA damage repair & {$[15,47]$} \\
\hline & Promotes oncogenic properties in cancer & {$[10,28,30]$} \\
\hline
\end{tabular}

Abbreviations: NHEJ non-homologous end joining; ROS reactive oxygen species

The higher the level of histone acetylation, the stronger the bond between BRD4 proteins and the chromatin, and the less likelihood of either isoform unbinding from the acetylated lysine [37]. Experimental conditions that disrupt the binding of endogenous BRD4 isoforms to the acetylated histones result in chromatin rupture, decompaction, and fragmentation [38].

Reports have found that BRD4-L bromodomains establish intermolecular interactions promoting a formation of BRD4-L-BRD4-L complexes [38], and might also be required for the establishment of nucleosome-nucleosome associations. Furthermore, BRD4-L's C-terminal (Fig. 1A) domain appears to be involved in ensuring proper organization and maintenance of chromatin, as it controls BRD4-L biding to acetylated histones [37, 38]. Therefore, the combination of both interactions, BRD4L-chromatin and BRD4-L-BRD4-L, appears to be essential for the higher-order chromatin organization (Fig. 4). Likewise, a synthetic protein [37] representing BRD4-S isoform (Fig. 1B) appears to be relevant for the structural support of the chromatin due to its stronger and more stable binding to histones, leading to a compact chromatin conformation [37]. Under experimental conditions, exogenous BRD4-S is capable of displacing endogenous forms of BRD4-L [38]. The conformational changes of chromatin structure caused by impairment of BRD4 


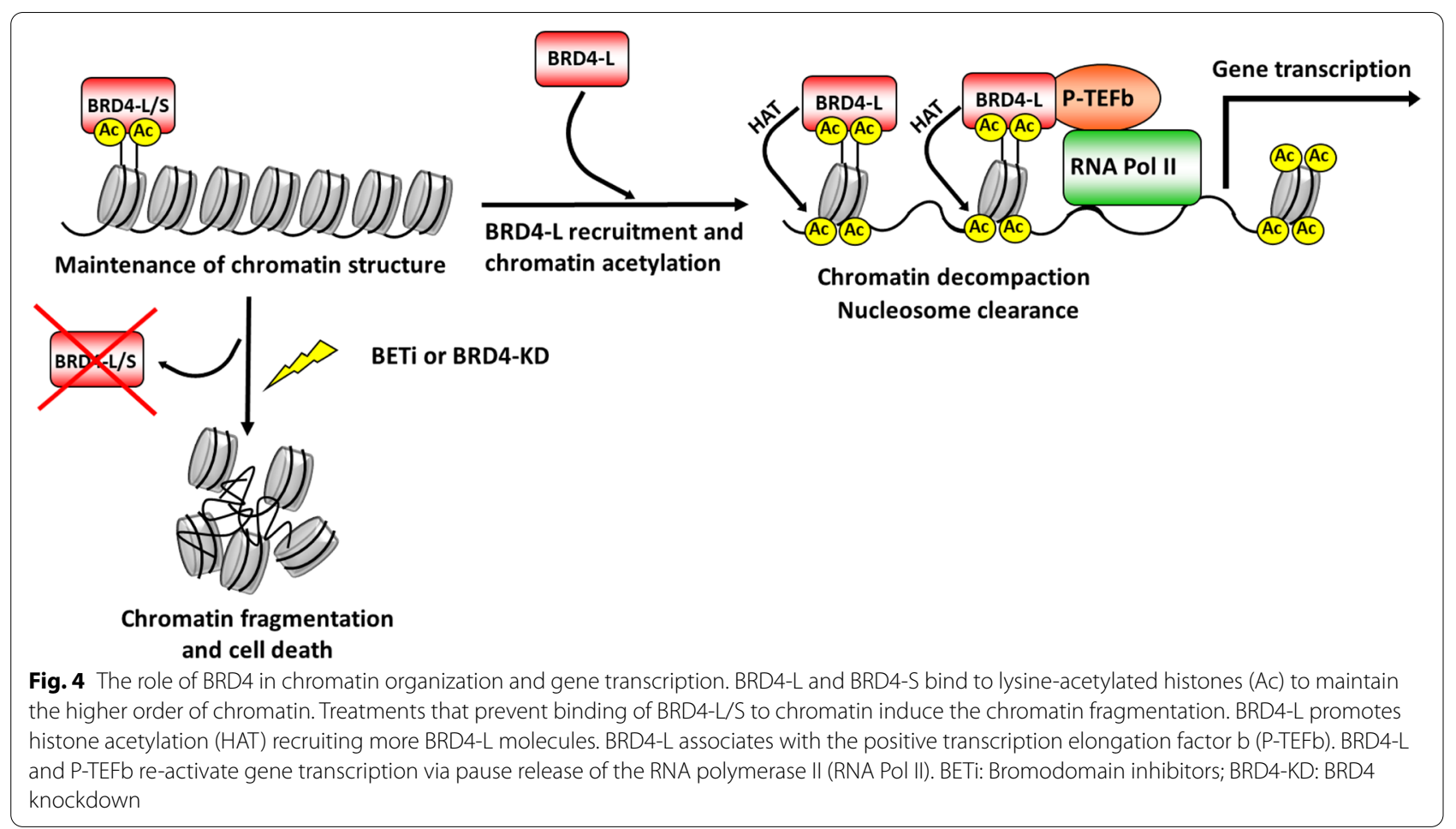

binding to the histones alters basic cellular functions, such as DNA replication and gene expression [51].

Recent studies showed that BRD4 might also play an active role in the histone lysine-acetylation [44]. One of the first indicators that BRD4 might function as a histone acetyltransferase (HAT) is that drug-induced depletion of BRD4 isoforms leads to hypoacetylation of histone H3 and $\mathrm{H} 4$ [52]. In addition, treatments with BETi are associated with reduced levels of acetylated histones [53]. In a recent study, Devaiah et al. [44] demonstrated that BRD4-L has an intrinsic HAT activity, carrying out the acetylation of $\mathrm{H} 3$ and $\mathrm{H} 4$ lysines of nucleosomal histones (Fig. 4). In addition, BRD4-L acetylates H3K122 residues located in the globular core of the H3 histone [44], where the DNA-histone bond is the strongest [54]. Through the histone acetylation process, BRD4-L actively evicts nucleosomes from chromatin, leading to decompaction of the chromatin structure, which becomes substantially more accessible to the transcriptional machinery. Therefore, by regulating the accessibility of chromatin to transcriptional complexes, BRD4-L plays an important role in inducing gene transcription.

\section{BRD4 isoforms as transcriptional co-activators}

During gene transcription, RNA Polymerase II ( $\mathrm{Pol}$ II) is recruited to gene promoter regions [55]. After transcription initiation, Poll II can promote RNA elongation or simply stall at the promoter proximal region, remaining in a paused state $[55,56]$. BRD4 plays an important role in the re-activation of paused Pol II via recruitment and activation of the Positive Transcription Elongation Factor b (P-TEFb) $[41,42]$. BRD4-L interacts with P-TEFb via its C-terminal domain (Fig. 1) [43], and it might bind to either or both subunits of P-TEFb known as CycT1 and Cdk9 [41, 43]. Together, BRD4-L and P-TEFb form a transcriptional activation complex (Fig. 3), which phosphorylates both serine sites of Pol II, initiating RNA elongation [57]. BRD4-L and P-TEFb interact throughout interphase, but dissociate during early mitosis [41], when the transcription process halts. These protein interactions increase dramatically in cells progressing from late mitosis to early G1 phase of the cell cycle [58]. These findings, and the presence of BRD4 isoforms associated with chromatin throughout mitosis [13], reinforce the role of BRD4-L as an epigenetic memory marker (Fig. 3), which acts by recruiting P-TEFb and quickly re-activating transcription after mitosis [58]. BRD4-L appears to have a more prominent role during post-mitotic transcriptional reactivation than during baseline interphase transcription, since the inhibition of BRD4-L does not significantly affect mRNA synthesis during interphase [36].

In addition to transcriptional activation of Pol II, BRD4 isoforms associate with the transcriptional co-factor MED1 and use phase-separation to form and compartmentalize condensates of high densities of transcriptional proteins [39] around super-enhancers (SE) [59]. SE are 
clusters of enhancers that regulate genes important in cell identities [60], including cancer cells [60,61]. The loss of condensate integrity significantly affects transcription on SE sites [59] BRD4-S was found to play a larger role in incorporating BRD4 condensation in the chromatin than BRD4-L [39]. BRD4-S organizes transcription factors through phase-separation to sustain transcription in chromatin for cancer cell proliferation [39].

\section{Opposite roles of BRD4 isoforms in DNA damage repair}

BRD4 is an important regulator of genes involved in DNA damage repair (DDR) 15, 16]. Li et al. [16] reported that the inhibition of BRD4 function (using BETi or shRNA) results in a decreased expression of genes involved in the DNA repair pathway known as non-homologous end joining (NHEJ) pathway. NHEJ is a mechanism of double strand breaks (DSB) repair that mediates direct rejoining of DNA strands with damaged termini [62]. In addition to transcriptional regulation of genes involved in DNA repair, BRD4-L directly binds and modulates the function of protein complexes involved in NHEJ [45]. In the presence of DSB, the chromatin undergoes modifications including $\mathrm{H} 4$ histone acetylation and $\mathrm{H} 2 \mathrm{AX}$ histone phosphorylation [15], which is followed by the recruitment of BRD4-L that binds to chromatin regions with damaged DNA. Then, BRD4-L functions as an anchorage for DNA repair proteins (Fig. 5), similarly to its role in transcriptional activation. Interestingly, BRD4-S has been reported to have an opposite effect in the DDR [15, 47], acting as an endogenous inhibitor of DNA repair complexes. BRD4-S binds stably to DNA molecules [37] and in the presence of DNA damage, it shields the chromatin from the DDR machinery [15, 47, 63]. In addition, BRD4-S recruits components of the condensing II complex inducing chromatin condensation, which impedes propagation of the DDR [47].

\section{BRD4 contribution to high-grade serous ovarian carcinoma pathogenesis Amplification of BRD4 in HGSOC patients}

Approximately $18 \%$ of the patients with high-grade serous ovarian carcinoma present somatic amplification of $B R D 4[4,10]$, which is often associated with increased $B R D 4$ gene and protein expression [10, 11, 64]. HGSOC patients harboring focal amplification of the chromosome 19, in regions that encompass BRD4 (19p13.2) [13,

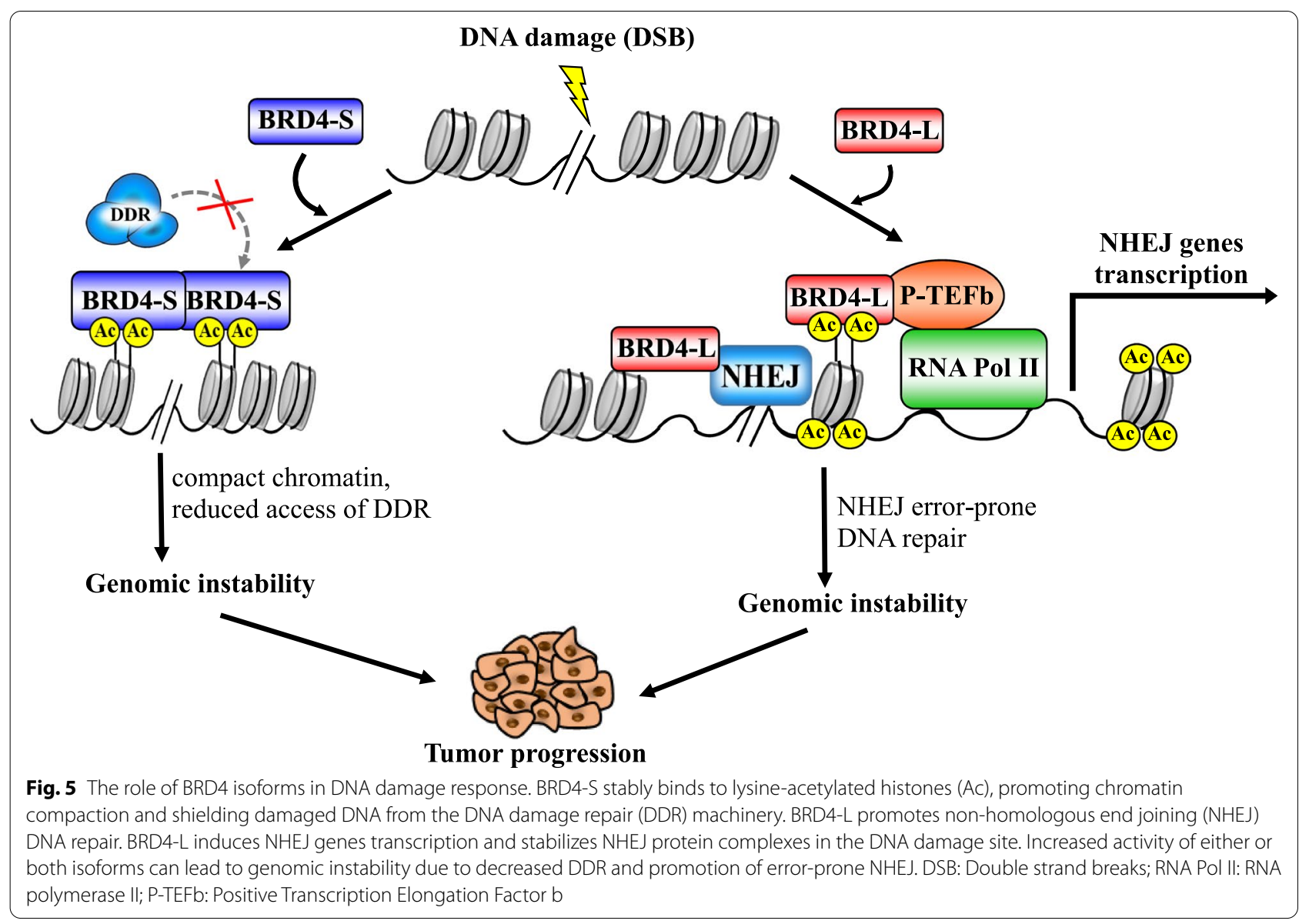


$19,65]$, tended to show advanced-stage ovarian cancer (97\% of the patients were diagnosed with stage III or IV tumors) [19]. These patients also presented considerable worse ovarian carcinoma prognosis. In consistency with this report, other studies have correlated BRD4amplification with worse patient survival [11, 20, 21, 64, 66]. Amongst chemotherapy resistant patients [19], the majority of patients (61\%) had BRD4-amplified tumors. As we will discuss further, BRD4 appears to be directly related to chemoresistance via regulation of ALDH activity [67] and promotion of DNA damage repair [68].

In HGSOC patients, the amplification of $B R D 4$ is often associated with the amplification of other genes $[11,19$, 21]. For instance the cyclin E 1 gene (CCNE1) [11] is amplified in $46-48 \%$ of patients with $B R D 4$ amplification $[20,21]$. Patients with co-amplification of both genes demonstrated worse survival than patients with only one of the genes amplified. Just as with BRD4, amplification of CCNE1 in these patients is accompanied by increased gene expression and protein levels of CCNE1 [11, 21]. CCNE1-amplified tumors are characterized by aberrant DNA replication, DNA replication stress and high levels of genomic instability [21]. Researchers suggest that the aberrant activation of cyclin pathway contribute to the genomic instability in patients harboring $B R D 4$ amplification $[13,19,65]$. Finally, it is important to point out that BRD4 amplification and BRCA1/2 mutations tend to be mutually exclusive in patients with HGSOC $[11,19]$, which suggests that the genomic instability in BRD4-amplified tumors is not due to the loss of BRCA functions.

\section{Isoform-specific functions of BRD4 in cancer}

A number of studies have correlated the amplification of BRD4 with HGSOC progression [10,64] and poor patient outcome [11, 20, 21, 64, 66]. Although there have been attempts to characterize the oncogenic effect of $B R D 4$ amplification in HGSOC [10], the exact mechanism by which BRD4 elicits ovarian tumor promotion is still a matter of scientific debate. Perhaps, better understanding of the effects of $B R D 4$ amplification on the initiation and progression of ovarian carcinoma relies on exploring the independent functions of BRD4 isoforms. Analysis of publically available TCGA data [4] revealed that both BRD4-L and BRD4-S are overexpressed in varying ratios in HGSOC patients whose tumors harbor BRD4 amplification [10]. Furthermore, Rhyasen et al. [10] reported that exogenous overexpression of both BRD4 isoforms in non-transformed ovarian epithelial cells showed robust colony formation in vitro, however, the short isoform of BRD4 showed a stronger tumorigenic potential than the long form of BRD4.
Emerging findings shed light on the importance of $\mathrm{BRD} 4$ isoforms in triple negative breast cancer (TNBC) $[28,29,32]$, which is molecularly similar to HGSOC, presenting widespread genomic instability and a high mutation rate of TP53 [4, 69]. A thorough study [28] performed in patient xenografts, cell lines and mouse models showed that, similar to what was observed in HGSOC [10], the ectopic expression of BRD4-S in TNBC tumors promotes oncogenic phenotype. Cells with BRD4-S showed increased cell proliferation, tumor growth and metastasis, while overexpression of BRD4-L suppressed these phenotypes. In addition, loss of BRD4-S function reduced cell proliferation, tumor growth and metastasis. Finally, the analysis of the percentage of individual BRD4 isoforms showed that TNBC patients with a higher BRD4-L to BRD4-S ratio presented a better overall survival than those with the lower ratio. The authors [28] concluded that BRD4 isoforms have opposing functions in $\mathrm{TNBC}$ and that post-transcriptional regulation may play a critical role influencing BRD4 protein isoform abundance during cancer progression.

Mechanistically, BRD4-S can exert different functions that depend on whether it associates to its target gene promoters or enhancers, and whether it interacts with BRD4-L [28]. In TNBC, in the absence of BRD4-L, BRD4-S interacts with homeobox transcription factors and binds to enhancer regions promoting transcription of genes that modulate components of the extracellular matrix (ECM). This leads to changes of the tumor microenvironment favoring disease progression. In the presence of BRD4-L, however, BRD4-S interacted with BRD4-L and acted as co-repressor, halting the expression of tumor promoting ECM genes and consequently suppressing tumor development.

In summary, it appears that the functions of BRD4-L and BRD4-S are substantially affected by the expression levels of each isoform and, potentially, by their mRNA splicing ratio [28]. In fact, some studies demonstrated that different genes have different requirements of BRD4$\mathrm{S}$ and BRD4-L for transcriptional activation [39]. It is possible that, just as with TNBC, the amplification of $B R D 4$ in HGSOC may lead to a shift in the splicing ratio of the two BRD4 isoforms resulting in BRD4-S overactivation that drives ovarian cancer pathogenesis and contribute to patients' poor prognosis (Fig. 2). However, further studies are needed to validate this hypothesis.

\section{BRD4-mediated transcriptional regulation of ovarian carcinoma oncogenes}

In ovarian cancer patients, the increased activity of $B R D 4$ is associated with the higher expression of a variety of oncogenes [10, 20,64, 66], many of which are positively regulated by BRD4 on transcriptional level [10, 20, 64]. 
$M Y C$ is one of the most studied oncogenes in HGSOC, which has been often associated with BRD4 [10, 20, 70], and whose expression in cancer can be down regulated by BETi [10, 71]. Chromatin immunoprecipitation experiments showed that BRD4 binds directly to $M Y C$ transcription start site, as well as enhancer regions in ovarian cancer cells [10]. Furthermore, it has been demonstrated that the amplification of BRD4 correlates with overexpression of MYC in HGSOC tumors from patients $[10,20]$ and in vitro transformed ovarian surface epithelium [10]. In addition, a treatment of ovarian tumors with BETi suppresses MYC activity, by impairing $M Y C$ gene expression $[10,72,73]$.

NOTCH3 is another oncogene of high relevance in ovarian carcinoma [74-77], which has been recently identified as being directly regulated by BRD4 in HGSOC [64]. NOTCH3 pathway activation in HGSOC correlates with ovarian cancer progression $[75,76]$ and contributes to epithelial-mesenchymal transition (EMT) and chemoresistance [74, 77]. BRD4 binds to the promoter regions of NOTCH3 in ovarian carcinoma [64], and inhibition of BRD4 activity is associated with lower expression of NOTCH3 mRNA and protein, as well as the expression NOTCH3 target genes.

Other studies revealed that induced expression of BRD4 isoforms in ovarian epithelial cells correlates with increased expression of NRG1 [10], which has been shown to participate in ovarian cancer cells proliferation and metastasis [78, 79]. The NRG1 gene encodes the protein Neuregulin 1, which is a glycoprotein with an epidermal growth factor-like domain that carries extracellular signals inside the cell by activating ErbB receptor tyrosine kinases. BRD4 directly binds to two independent NRG1 promoter and enhancer sites [10], and NRG1 has been identified as a direct effector of BRD4 in ovarian carcinoma. Recent reports have found NRG1 to be a key gene associated with chemotherapy response in ovarian carcinoma and its downregulation correlated with tumor sensitivity to treatment [80]. Hence, transcriptional modulation of the NRG1 pathway might be one of the mechanisms through which BRD4 plays a role in ovarian cancer patients' response to chemotherapy, however, further studies are required to validate such mechanism.

\section{Modulation of oxidative stress response in $\mathrm{HGSOC}$}

Oxidative stress is considered a secondary hallmark of cancer [8] that plays an important role in ovarian carcinoma pathogenesis [81], often being associated with a development of chemoresistance in cancer cells [82, 83]. BRD4 is involved in the mechanism of cellular response to oxidative stress, via regulation of the KEAP1/NRF2 signaling network $[18,46]$, which is one of the major oxidative stress response pathways [84]. Under baseline conditions, BRD4 constitutively binds to promoter sites of genes regulated by the transcription factor NRF2 [18, 46], and plays a role as both a gene expression inhibitor as well as activator, a mechanism that is cell-type dependent [18]. One example of genes regulated by BRD4-NRF2 axis is the heme oxygenase 1 (HMOX1) encoding an inducible enzyme HMOX1 that actively eliminates endogenous ROS [85]. HMOX1 is considered to be an oncogene in ovarian cancer [81] and its high expression promotes proliferation in ovarian carcinoma cells [86]. In addition, HMOX1 overexpression has been found to be a predictor of worse prognosis in ovarian carcinoma patients [86]. Studies also showed that BRD4 can directly bind to $H M O X 1$ promoter region, in an KEAP1/ NRF2-independent manner stimulating HMOX1 gene expression, which then participates in the maintenance of endogenous ROS levels $[18,46]$.

\section{Promotion of genomic instability and chemoresistance in HGSOC}

Impaired DNA repair mechanisms can lead to genomic instability [87]. This is particularly the case in HGSOC, which is characterized by high genomic instability $[4,62]$. Recent studies indicate that genomically instable cancer phenotype in patients with BRD4 amplification could be attributed to less efficient DNA repair mechanisms. For instance, in DNA damage conditions, BRD4 mediates error-prone DNA repair via NHEJ pathway $[16,45,62]$ rather than error-free HR pathway. NHEJ is defective in more than $40 \%$ of ovarian carcinoma patient, which is independent of $\mathrm{HR}$ function [88]. In addition, the short isoform of BRD4 (BRD4-S) effectively blocks DNA repair by preventing recruitment of DDR complexes to chromatin with damaged DNA, thereby diminishing DNA repair deficiency $[15,47,63]$.

Furthermore, BRD4 role in DDR might also correlate with the development of resistance in BRD4-amplified patients to DNA-damage inducing chemotherapy [19]. One of the most studied resistance mechanisms of platinum-based chemotherapy is increased DNA repair [89]. The importance of DNA repair in HGSOC is evidenced by the mechanism of action of the most effective chemotherapies inducing DNA damage, and the high incidence of DNA repair dysfunction in HGSOC [89]. BRD4 regulates single strand breaks repair by activating the protein kinase CHK1 [68], which triggers checkpoint signals to promote delay of cell cycle progression and restoration of stalled replication forks [90, 91]. Ovarian cancer cells treated with BETi show a timedependent reduction in the levels of pCHK1, suggesting that BRD4 can regulate CHK1 signaling in response to DNA replication stress [68]. 
Another mechanism through which amplification of BRD4 in HGSOC patients might lead to chemoresistance is modulation of aldehyde dehydrogenase (ALDH) activity, which is regulated on transcriptional level. Reduced expression of aldehyde dehydrogenase gene ALDH1A1 is associated with stemness properties as well as platinum resistance of ovarian cancer cells [91]. Cells with decreased expression of ALDH1A1 presented spontaneous DNA damage, in addition to dephosphorylation and consequent de-activation of CHK1, which contributed to chemosensitization of ovarian cancer cells [92]. Furthermore, ovarian cancer cells with higher activity of ALDH showed enhanced DNA repair, suggesting an important role for this protein in resistance to druginduced DNA damage $[92,93]$. BRD4 has been shown to regulate ALDH1A1 expression at a transcriptional level [67]. Increased expression of BRD4 in ovarian cancer cells resulted in an increase of ALDH activity [94], while diminished BRD4 activity decreased ALDH activity by direct suppression of ALDH1A1 gene expression [67].

\section{Induction of epithelial-mesenchymal transition}

Recent reports demonstrated that BRD4 is directly involved in the metastatic process in HGSOC patients [95]. The downregulation of BRD4 activity markedly reduced the invasive properties of ovarian cancer cell lines, while BRD4 upregulation augmented cell migration and invasion. The development of ovarian cancer metastasis involves several steps that often relay on the process of epithelial-mesenchymal transition [96, 97]. One of the early events involved in EMT is the loss of E-cadherin due to direct transcription inhibition [98-100] by transcriptional repressors such as Sip1/ZEB2, Snail, and Slug $[97,101]$. Although there are no studies that specifically elucidate the involvement of BRD4 in the regulation of Snail1 and Slug in ovarian carcinoma, the mechanism by which these genes promote EMT is relatively conserved amongst different types of tumors [100]. A lung cancer study demonstrated that BRD4 is involved in the promotion of EMT [102], via regulation of these transcriptional repressors. The histone acetyltransferase PCAF promotes acetylation of the transcription factor ISX which interacts with the bromodomains of BRD4, forming a transcriptional activating complex. The PCAF-ISX-BRD4 complex binds to the promoter regions of Snail1 and Slug inducing their transcription [102] and promoting EMT characteristics of the tumor cells. It is plausible to speculate that a similar mechanism is at play in HGSOC patients.

\section{BRD4 as a therapeutic target in ovarian carcinoma}

To ablate the activity of bromodomain proteins in ovarian carcinoma, particularly BRD4, a variety of smallmolecule BETi have been developed and tested [10, 64,
67, 103-106]. The JQ1 compound was shown to bind to the bromodomains of BRD4 (Fig. 1), with higher affinity and stability than to other members of the BET family [107] and it has been largely used in pre-clinical studies testing BETi in ovarian cancer $[67,68,72,104-106,108$, 109]. JQ1 has been shown to suppress the expression of several cancer related genes in ovarian carcinoma $[67,72$, $105,110]$. Although JQ1 has been reported to be a cytostatic drug suppressing ovarian cancer cell proliferation $[72,104,106,109,110]$, some studies suggest that it also induces apoptosis, especially when used in combination with other drugs [64, 67, 72, 105, 109].

I-BET151 is another small-molecule inhibitor commonly tested in ovarian carcinoma [111-113]. I-BET151 was reported to impair tumor growth by displacing BRD4 from the chromatin, which reduced the expression of the Forkhead box protein M1 (FoxM1) transcription factor [112, 113]. FoxM1 induces the expression of genes involved in cell proliferation, therefore down-regulation of FoxM1 inhibits tumor growth [112, 113]. In addition, I-BET151 inhibits migration and invasion of ovarian cancer cells by downregulation of EMT master regulators, which suppresses the expression of matrix metalloproteinases (MMPs) such as MMP2 and MMP9 [111, 112]. MMPs are enzymes that degrade and modify the ECM mediating cell motility, invasion, and EMT phenotype [114]. Finally, the use of I-BET151 in combination with cisplatin was shown to augment the inhibitory effect of cisplatin in ovarian cancer cell lines, considerably reducing cell proliferation [112].

Combination therapy with BETi can be also very effective in overcoming chemoresistance in pre-clinical settings [72, 112, 115, 116]. JQ1, for example, effectively increases sensitivity to cisplatin of platinum-resistant ovarian cancer cell line in vitro [72]. Combination of JQ1 or BET151 with cisplatin significantly reduced cell proliferation, even in highly chemo-resistant ovarian cancer cell lines [72,112] and primary tumor cells [72]. However, the successful use of combination therapy using BETi in ovarian cancer goes beyond sensitization of tumors to platinum drugs. Pre-clinical studies demonstrated that the pharmaceutical inhibition of BRD4 or BRD4 knockdown contribute to homologous recombination defects (HRD), sensitizing ovarian carcinoma cells to Poly (ADP-ribose) polymerase inhibitors (PARPi), regardless of their BRCA mutation status $[117,118]$. When treated with JQ1, OVCAR3 cell line demonstrated a significant increase in the expression of DNA damage repair genes and activation of the cell cycle checkpoint genes [118]. Administration of PARPi olaparib to JQ1 treated cells induced high levels of apoptosis. The cell death induced by JQ1-olaparib combination therapy was more profound than after the 
treatment with each drug alone indicating a synergistic antitumor efficacy. In addition, co-treatment of cancer cells with BETi and PARPi reversed the PARP-resistance in both in vitro and in vivo studies [117].

BETi have been also frequently combined with tyrosine kinase inhibitors (TKi), such as ponatinib and lapatinib $[10,106]$. Tyrosine kinases are key regulators of mitogenic signaling pathways frequently implicated in oncogenesis [119]. Treatment with TKi inhibit tumor growth by suppressing essential cellular processes such as proliferation, survival and invasion. Ovarian tumor models exposed to combination therapies such as ponatinib (TKi) and dBET1 (BRD4 degrader) [106], or lapatnib (TKi) and AZD5153 (BETi) [10] induced more robust cell apoptosis and tumor regression than each drug alone. Finally, the combination of BETi with MEK inhibitors (MEKi) has been shown to efficiently and synergistically suppress ovarian carcinoma growth by inducing cell death both in vitro and in vivo [109, 120]. MEKi ablates the activity of the RAS/MAPK signaling pathway involved in cell growth and tumorigenesis [121], which has been found to be significantly increased in HGSOC [122].

Despite the extensive use of BETi in pre-clinical studies including ovarian cancer, the knowledge around the applicability of these compounds in the actual clinical set up is very limited. Currently, there are 9 reportedly active clinical trials studying BETi as anticancer drugs [27] and two of those studies rely on the participation of ovarian carcinoma patients $[25,26]$. It appears that amongst the challenges associated with the use of BETi in patients, considerable side effects, such as thrombocytopenia, asthenia, fatigue, as well as digestive discomfort (nausea, anorexia, diarrhea, and vomiting) have been commonly reported by clinical studies using BETi in humans [23, 123-127]. Nonetheless, because pre-clinical data in ovarian carcinoma are so encouraging [22], especially when used in combination therapy, attempts to successfully implement BETi treatments continue to be made [127]. Table 2 summarizes the most recent information on clinical studies developed with participation of ovarian cancer patients.

\section{BETi limitations}

Despite the large number of studies proposing BETi compounds as successful alternative treatment for ovarian carcinoma and other types of cancer [22], BETi have limitations. One caveat to BETi therapy is that ovarian carcinoma cells may acquire resistance following sustained treatment with BETi [110, 128-131]. JQ1 resistance, for example, can be achieved through remodeling of epigenetic markers and reactivation of the transcription of key BRD4 target genes [128]. Some reports have found that resistance to BETi can be mediated by adaptive kinome reprogramming, via activation of compensatory pro-survival kinase networks, which overcomes BET protein inhibition [110]. However, this phenotype can be reversed with the use of drugs that block respective kinases, preventing or delaying the development of resistance and enhancing the efficacy of BETi therapy. In addition, evaluation of apoptotic and proliferative response in 2 sensitive and 2 resistant cell lines to JQ1 showed that this BET inhibitor induced pro-survival autophagy via inactivation of the Akt/mTOR pathway, elucidating another potential mechanism of resistance in ovarian cancer cells [130]. As an alternative to the use of BETi, the use of proteolysis targeting chimeras (PROTACS) has been proposed with the intention to degrade BRD4 $[129,132,133]$. PROTACS, such as dBET1 and dBET6, selectively and substoichiometrically degraded BRD4 and demonstrated to be more potent antitumor activity in ovarian carcinoma than the small molecule inhibitors $[132,133]$.

One of the concerns in using BETi is that these drugs also show some inhibitory activity towards other members of the BET family [107, 129]. For instance, the use of high doses of BETi leads to a pan-BET inhibition, which alters a number of signaling pathways essential for normal cell function potentiating undesired side effects $[128,129,134]$. In addition, there is a likelihood of inconsistency in reports describing BRD4 functions if the BRD4 function attribution was solely based on the use of BET inhibitors [128, 135]. Therefore, it is paramount that basic and pre-clinical studies using BETi be performed in parallel with other forms

Table 2 Clinical studies involving patients with ovarian cancer

\begin{tabular}{llll}
\hline BET inhibitor & Malignancy eligibility & Response & Ref. \\
\hline INCB054329 & HGSOC (solid tumors) & PD as best response & [23] \\
INCB057643 & BRCA ${ }^{W T}$ HGSOC (solid tumors) & PD as best response & {$[23]$} \\
ODM-207 & HGSOC & No result reported for HGSOC & {$[24]$} \\
RO6870810 & Advanced OC & No result reported & {$[25]$} \\
BMS-986158 & BRCA & Un OC (advanced tumors) & Under development, no results yet \\
ZEN-3694 & Platinum-resistant OC and refractory OC & Not yet recruiting & {$[26]$} \\
\hline
\end{tabular}

Abbreviations: HGSOC high-grade serous ovarian carcinoma; WT wild type; OC ovarian carcinoma; PD progressive disease 
of BRD4 inhibition, such as siRNA and complemented with silencing of the other members of BET $[117,136]$.

\section{Conclusion}

In summary, BRD4 is a dynamic constitutively expressed protein, which participates in a variety of homeostatic processes in healthy cells, via both its chromatin binding function and its transcriptional coactivator role. Amplification of BRD4 is amongst the top five most common somatic amplification occurring in HGSOC, and it correlates with poor patient prognosis. However, further studies are necessary to clarify the mechanisms behind the role of BRD4 in ovarian carcinoma. Because amplification of BRD4 is more common in older patients, with advanced stages of the disease, it is likely that BRD4 plays a more pertinent role in the progression of HGSOC than in the initiation of the disease. Studies in breast cancer have demonstrated a compelling evidence that BRD4 isoforms have distinct and even contradictive functions [28], providing an insight into mechanisms that are likely at play in other tumor types including ovarian carcinoma. Therefore, it is important to expand this area of research in HGSOC to elucidate the different functions of individual BRD4 isoforms, establishing a relationship between their splicing ratio and disease progression, as well as patients' prognosis. Lastly, it would be informative to initiate mechanistic studies investigating the physiological role of BRD4 isoforms in healthy cells, since very little is known about BRD4 isoforms (especially BRD4$S)$ in the non-pathological context.

\section{Abbreviations \\ $\mathrm{BET}$ : Bromodomain and extra-terminal domain family of proteins; $\mathrm{BET}$ : Bromodomain inhibitors; BRD4: Bromodomain-containing protein 4; BRD4-L: BRD4 long; BRD4-S: BRD4 short; CCNE1: Cyclin E1; DBS: Double strand breaks; DDR: DNA damage repair; ECM: Extracellular matrix; EMT: Epithelial-mesen- chymal transition; EN1: Homeobox protein engrailed-1; FoxM1: Forkhead box protein M1; H3K14Ac: Histone H3 acetylate in lysine 14; H4K5Ac: Histone $\mathrm{H} 4$ acetylate in lysine 5; H4K8Ac: Histone $\mathrm{H} 4$ acetylate in lysine 8; H4K12Ac: Histone $\mathrm{H} 12$ acetylate in lysine 12; HAT: Histone acetyltransferase; HGSOC: High-grade serous ovarian carcinoma; HMBA: Hexamethylene bisacetamide; HMOX1: Heme oxygenase 1; HR: Homologous recombination; MCAP: Mitotic chromosome-associated protein; MEKi: MEK inhibitors; MMPs: Metalloprotein- ases; NHEJ: Non-homologous end joining; PARPi: Poly (ADP-ribose) polymer- ase inhibitors; PRG: Primary response genes; Pol II: RNA polymerase Il; P-TEFb: Positive transcriptional elongation factor b; ROS: Reactive oxygen species; $\mathrm{SE}$ : Super-enhancers; TCGA: The cancer genome atlas; TKi: Tyrosine kinase inhibi- tors; TNBC: Triple negative breast cancer; YAP:Yes1 associated transcriptional regulator.}

\section{Acknowledgements}

We would like to thank the Oklahoma Medical Research Foundation (OMRF) for flexibility and support in this last year. We would also like to thank our lab members for fruitful discussions and for keeping our science moving forward during pandemic times.

\section{Authors' contributions}

ALDB performed literature review, wrote the manuscript, drew and edited the figures and created the Table. MB wrote and reviewed the manuscript, drew and edited the figures. Both authors read and approved the final manuscript.

\section{Funding}

Content reported in this publication was supported by the Oklahoma Medical Research Foundation.

Availability of data and materials

Not applicable.

\section{Declarations}

Ethics approval and consent to participate

Not applicable.

Consent for publication

Not applicable.

\section{Competing interests}

Not applicable.

Received: 29 June 2021 Accepted: 11 September 2021

Published online: 10 November 2021

References

1. Siegel RL, Miller KD. Cancer Statistics. 2019. CA Cancer J Clin. 2019;69(1):7-34.

2. Matsuo K, Machida H, Matsuzaki S, Grubbs BH, Klar M, Roman LD, et al. Evolving population-based statistics for rare epithelial ovarian cancers. Gynecol Oncol. 2020;157(1):3-11. Available from: https://doi. org/10.1016/j.ygyno.2019.11.122.

3. Torre LA, Trabert B, DeSantis CE, Miller KD, Samimi G, Runowicz CD, et al. Ovarian cancer statistics, 2018. CA Cancer J Clin. 2018;68(4):284-96.

4. Bell D, Berchuck A, Birrer M, Thomson E. Integrated genomic analyses of ovarian carcinoma. Nature. 2011;474(7353):609-15. Available from: http://www.nature.com/articles/nature10166.

5. Ciriello G, Miller ML, Aksoy BA, Senbabaoglu Y, Schultz N, Sander C. Emerging landscape of oncogenic signatures across human cancers. Nat Genet. 2013;45(10):1127-33. Available from: http://www.nature. com/articles/ng.2762.

6. Pal T, Permuth-Wey J, Betts JA, Krischer JP, Fiorica J, Arango H, et al. BRCA1 and BRCA2 mutations account for a large proportion of ovarian carcinoma cases. Cancer. 2005;104(12):2807-16.

7. Chen J, Silver DP, Walpita D, Cantor SB, Gazdar AF, Tomlinson G, et al. Stable interaction between the products of the BRCA1 and BRCA2 tumor suppressor genes in mitotic and meiotic cells. Mol Cell. 1998;2(3):317-28.

8. Negrini S, Gorgoulis VG, Halazonetis TD. Genomic instability an evolving hallmark of cancer. Nat Rev Mol Cell Biol. 2010.

9. Bast RC, Hennessy B, Mills GB. The biology of ovarian cancer: new opportunities for translation. Nat Rev Cancer. 2009;9(6):415-28. Available from: http://www.nature.com/articles/nrc2644.

10. Rhyasen GW, Yao Y, Zhang J, Dulak A, Castriotta L, Jacques K, et al. BRD4 amplification facilitates an oncogenic gene expression program in high-grade serous ovarian cancer and confers sensitivity to BET inhibitors. PLoS One. 2018;13(7):1-23.

11. Goundiam O, Gestraud P, Popova T, De La Motte RT, Fourchotte V, Gentien D, et al. Histo-genomic stratification reveals the frequent amplification/overexpression of CCNE1 and BRD4 genes in non-BRCAness high grade ovarian carcinoma. Int J Cancer. 2015;137(8):1890-900.

12. Thorpe KL, Abdulla S, Kaufman J, Trowsdale J, Beck S. Phylogeny and structure of theRING3 gene. Immunogenetics 1996;44(5):391-6. Available from: http://link.springer.com/10.1007/BF02602785. 
13. Dey A, Ellenberg J, Farina A, Coleman AE, Maruyama T, Sciortino S, et al. A Bromodomain protein, MCAP, associates with mitotic chromosomes and affects G2-to-M transition. Mol Cell Biol. 2000;20(17):6537-49.

14. Dhalluin C, Carlson JE, Zeng L, He C, Aggarwal AK, Zhou MM. Structure and ligand of a histone acetyltransferase bromodomain. Nature. 1999;399(6735):491-6.

15. Donati B, Lorenzini E, Ciarrocchi A. BRD4 and Cancer: going beyond transcriptional regulation. Mol Cancer. 2018;17(1):1-13.

16. Li X, Baek G, Ramanand SG, Sharp A, Gao Y, Yuan W, et al. BRD4 promotes DNA repair and mediates the formation of TMPRSS2-ERG gene rearrangements in prostate Cancer. Cell Rep. 2018;22(3):796-808. Available from: https://linkinghub.elsevier.com/retrieve/pii/S221112471 7319150.

17. Hargreaves DC, Horng T, Medzhitov R. Control of inducible gene expression by signal-dependent transcriptional elongation. J End-to-End-Test. 2009;138(1):129-45

18. Michaeloudes C, Mercado N, Clarke C, Bhavsar PK, lan M. Bromodomain and extra-terminal (BET) proteins suppress nuclear factor E2-related factor 2 (Nrf2) -mediated antioxidant gene expression. J Immunol. 2014;192(10):4913-20.

19. Sung $\mathrm{CO}$, Song $\mathbb{H}$, Sohn I. A distinctive ovarian cancer molecular subgroup characterized by poor prognosis and somatic focal copy number amplifications at chromosome 19. Gynecol Oncol 2014;132(2):343-50. Available from: https://doi.org/10.1016/j.ygyno.2013.11.036

20. Ucar D, Lin DI. Amplification of the bromodomain-containing protein 4 gene in ovarian high-grade serous carcinoma is associated with worse prognosis and survival. Mol Clin Oncol 2015;3(6):1291-4. Available from: https://www.spandidos-publications.com/10.3892/mco.2015.622.

21. Petersen S, Wilson AJ, Hirst J, Roby KF, Fadare O, Crispens MA, et al. Gynecologic oncology CCNE1 and BRD4 co-ampli fi cation in highgrade serous ovarian cancer is associated with poor clinical outcomes. Gynecol Oncol]. 2020;(xxxx):1-6. Available from: https://doi.org/10. 1016/j.ygyno.2020.01.038

22. Andrikopoulou A, Liontos M, Koutsoukos K, Dimopoulos M-A, Zagouri F. Clinical perspectives of BET inhibition in ovarian cancer. Cell Oncol. 2021 Jan 19; Available from: http://link.springer.com/10.1007/ s13402-020-00578-6.

23. Falchook G, Rosen S, LoRusso P, Watts J, Gupta S, Coombs CC, et al. Development of 2 bromodomain and extraterminal inhibitors with distinct pharmacokinetic and pharmacodynamic profiles for the treatment of advanced malignancies a C. Clin Cancer Res. 2020;26(6):1247-57.

24. Ameratunga M, Braña I, Bono P, Postel-Vinay S, Plummer R, Aspegren $J$, et al. First-in-human phase 1 open label study of the BET inhibitor ODM-207 in patients with selected solid tumours. Br J Cancer 2020;123(12):1730-6. Available from: http://dx.doi.org/10.1038/ s41416-020-01077-z.

25. Roche H-L. A Study to Evaluate the Safety, Pharmacokinetics and Clinical Activity of RO6870810 and Atezolizumab (PD-L1 Antibody) in Participants With Advanced Ovarian Cancer or Triple Negative Breast Cancer. ClinicaltrialsGov [Internet]. 2019;(Cdc):November 8, 2017-February 26, 2019. Available from: https://clinicaltrials.gov/show/NCT03 292172.

26. Squibb B. Study of BMS-986158 in Subjects With Select Advanced Cancers ( BET ). 2021;(Cdc):1-10. Available from: https://clinicaltrials.gov/ $\mathrm{ct} 2 /$ show/NCT02419417?term $=$ BET+inhibitors\&recrs $=$ abdf\&draw $=2 \&$ rank $=7$.

27. Clinical Trials .Gov [Internet]. 2021. p. 1-6. Available from: https://clini caltrials.gov/ct2/results?term $=B E T+$ inhibitors\&Search $=$ Apply\&recrs $=$ $b \& r e c r s=a \& r e c r s=d \& a g e \_v=\& g n d r=\&$ type $=\& r s \mid t=$.

28. Wu SY, Lee CF, Lai HT, Yu CT, Lee JE, Zuo H, et al. Opposing functions of BRD4 isoforms in breast Cancer. Mol Cell. 2020;78(6):1114-32.e10. Available from: https://doi.org/10.1016/j.molcel.2020.04.034

29. Alsarraj J, Walker RC, Webster JD, Geiger TR, Crawford NPS, Simpson RM, et al. Deletion of the proline-rich region of the murine metastasis susceptibility gene Brd4 promotes epithelial-to-mesenchymal transitionand stem cell-like conversion. Cancer Res 2011;71(8):3121-31. Available from: http://cancerres.aacrjournals.org/cgi/doi/10.1158/0008-5472. CAN-10-4417.

30. Crawford NPS, Alsarraj J, Lukes L, Walker RC, Officewala JS, Yang HH, et al. Bromodomain 4 activation predicts breast cancer survival. Proc Natl Acad Sci U S A. 2008:105(17):6380-5.
31. Fernandez P, Scaffidi P, Markert E, Lee JH, Rane S, Misteli T. Transformation resistance in a premature aging disorder identifies a tumorprotective function of BRD4. Cell Rep 2014;9(1):248-60. Available from: https://doi.org/10.1016/j.celrep.2014.08.069.

32. Zhang S, Roeder RG. The long and the short of BRD4: two Tales in breast Cancer. Mol Cell. 2020;78(6):993-5. Available from: https://doi.org/10. 1016/.j.molcel.2020.05.033.

33. Hendzel MJ, Wei Y, Mancini MA, Van Hooser A, Ranalli T, Brinkley BR, et al. Mitosis-specific phosphorylation of histone $\mathrm{H} 3$ initiates primarily within pericentromeric heterochromatin during $\mathrm{G} 2$ and spreads in an ordered fashion coincident with mitotic chromosome condensation. Chromosoma. 1997;106(6):348-60.

34. Wei Y, Yu L, Bowen J, Gorovsky MA, David AC. Phosphorylation of histone $\mathrm{H} 3$ is required for proper chromosome condensation and segregation. Cell. 1999;97(1):99-109.

35. Dey A, Nishiyama A, Karpova T, McNally J, Ozato K. Brd4 marks select genes on mitotic chromatin and directs postmitotic transcription. Zheng Y, editor. Mol Biol Cell. 2009;20(23):4899-909. Available from: www.molbiolcell.org/cgi/doi/10.1091/mbc.E09-05-0380.

36. Zhao R, Nakamura T, Fu Y, Lazar Z, Spector DL. Gene bookmarking accelerates the kinetics of post-mitotic transcriptional re-activation. Nat Cell Biol. 2011;13(11):1295-304 Available from: http://www.nature.com/ articles/ncb2341.

37. Dey A, Chitsaz F, Abbasi A, Misteli T, Ozato K. The double bromodomain protein Brd4 binds to acetylated chromatin during interphase and mitosis. Proc Natl Acad Sci U S A. 2003;100(15):8758-63.

38. Wang R, Li Q, Helfer CM, Jiao J, You J. Bromodomain protein Brd4 associated with acetylated chromatin is important for maintenance of higher-order chromatin structure. J Biol Chem. 2012;287(14):10738-52.

39. Han X, Yu D, Gu R, Jia Y, Wang Q, Jaganathan A, et al. Roles of the BRD4 short isoform in phase separation and active gene transcription. Nat Struct Mol Biol. 2020;27(4):333-41.

40. French CA, Miyoshi I, Kubonishi I, Grier HE, Perez-Atayde AR, Fletcher JA. BRD4-NUT fusion oncogene: a novel mechanism in aggressive carcinoma. Cancer Res. 2003;63(2):304-7.

41. Jang KM, Mochizuki K, Zhou M, Jeong HS, Brady JN, Ozato K. The bromodomain protein $\mathrm{Brd} 4$ is a positive regulatory component of $\mathrm{P}$-TEFb and stimulates RNA polymerase II-dependent transcription. Mol Cell. 2005;19(4):523-34.

42. Yang Z, Yik JHN, Chen R, He N, Moon KJ, Ozato K, et al. Recruitment of P-TEFb for stimulation of transcriptional elongation by the bromodomain protein Brd4. Mol Cell. 2005;19(4):535-45.

43. Bisgrove DA, Mahmoudi T, Henklein P, Verdin E. Conserved P-TEFb-interacting domain of BRD4 inhibits HIV transcription. Proc Natl Acad Sci U S A. 2007;104(34):13690-5.

44. Devaiah BN, Case-Borden C, Gegonne A, Hsu CH, Chen Q, Meerzaman D, et al. BRD4 is a histone acetyltransferase that evicts nucleosomes from chromatin. Nat Struct Mol Biol. 2016;23(6):540-8. Available from: http://www.nature.com/articles/nsmb.3228.

45. Stanlie A, Yousif AS, Akiyama H, Honjo T, Begum NA. Chromatin reader Brd4 functions in Ig class switching as a repair complex adaptor of nonhomologous end-joining. Mol Cell 2014;55(1):97-110. Available from: http://dx.doi.org/10.1016/.j.molcel.2014.05.018.

46. Hussong M, Börno ST, Kerick M, Wunderlich A, Franz A, Sültmann H, et al. The bromodomain protein BRD4 regulates the KEAP1/NRF2dependent oxidative stress response. Cell Death Dis. 2014;5(4):1-11.

47. Floyd SR, Pacold ME, Huang Q, Clarke SM, Lam FC, Cannell IG, et al. The bromodomain protein $\mathrm{Brd} 4$ insulates chromatin from DNA damage signalling. Nature. 2013;498(7453):246-50. Available from: http://www. nature.com/articles/nature12147.

48. Mujtaba S, Zeng L, Zhou MM. Structure and acetyl-lysine recognition of the bromodomain. Oncogene. 2007;26(37):5521-7.

49. Sanchez R, Zhou M-M. The role of human bromodomains in chromatin biology and gene transcription. Curr Opin Drug Discov Devel. 2009;12(5):659-65 Available from: http://www.ncbi.nlm.nih.gov/ pubmed/19736624

50. Hu X, Lu X, Liu R, Ai N, Cao Z, Li Y, et al. Histone cross-talk connects protein phosphatase 1a (PP1 a) and histone deacetylase (HDAC) pathways to regulate the functional transition of bromodomaincontaining 4 (BRD4) for inducible gene expression. J Biol Chem. 2014;289(33):23154-67. 
51. Almeida R, Fernández-Justel JM, Santa-María C, Cadoret JC, CanoAroca L, Lombraña R, et al. Chromatin conformation regulates the coordination between DNA replication and transcription. Nat Commun 2018;9(1):1-14. Available from: http://dx.doi.org/10.1038/ s41467-018-03539-8.

52. Nishiyama A, Dey A, Miyazaki J, Ozato K. Brd4 is required for recovery from Antimicrotubule drug-induced mitotic arrest: preservation of acetylated chromatin. Mol Biol Cell 2006;17(2):814-23. Available from: https://www.molbiolcell.org/doi/10.1091/mbc.e05-08-0729.

53. Nicodeme E, Jeffrey KL, Schaefer U, Beinke S, Dewell S, Chung C, et al. Suppression of inflammation by a synthetic histone mimic. Nature. 2010;468(7327):1119-23 Available from: http://www.nature.com/artic les/nature09589.

54. Tropberger P, Pott S, Keller C, Kamieniarz-Gdula K, Caron M, Richter F, et al. Regulation of transcription through acetylation of H3K122 on the lateral surface of the histone octamer. Cell. 2013;152(4):859-72.

55. Nechaev S, Adelman K. Pol II waiting in the starting gates: regulating the transition from transcription initiation into productive elongation. Biochim Biophys Acta - Gene Regul Mech. 2011;1809(1):34-45 Available from: https://linkinghub.elsevier.com/retrieve/pii/S187493991 0001392.

56. Muse GW, Gilchrist DA, Nechaev S, Shah R, Parker JS, Grissom SF, et al. RNA polymerase is poised for activation across the genome. Nat Genet. 2007;39(12):1507-11 Available from: http://www.nature.com/articles/ ng.2007.21

57. Devaiah BN, Lewis BA, Cherman N, Hewitt MC, Albrecht BK, Robey PG, et al. BRD4 is an atypical kinase that phosphorylates Serine2 of the RNA polymerase II carboxy-terminal domain. Proc Natl Acad Sci U S A. 2012;109(18):6927-32.

58. Yang Z, He N, Zhou Q. Brd4 recruits P-TEFb to chromosomes at late mitosis to promote $\mathrm{G} 1$ gene expression and cell cycle progression. Mol Cell Biol. 2008;28(3):967-76.

59. Sabari BR, Dall'Agnese A, Boija A, Klein IA, Coffey EL, Shrinivas K, et al. Coactivator condensation at super-enhancers links phase separation and gene control. Science (80- ). 2018;361(6400):1-17.

60. Hnisz D, Abraham B, Lee T, Lau A, Saint-Andre V, Sigova A, et al. Transcriptional super-enhancers connected to cell identity and disease. Cell. 2014;155(4):1-24.

61. Lovén J, Hoke HA, Lin CY, Lau A, Orlando DA, Vakoc CR, et al. Selective inhibition of tumor oncogenes by disruption of super-enhancers. Cell. 2013;153(2):320-34.

62. Gee ME, Faraahi Z, McCormick A, Edmondson RJ. DNA damage repair in ovarian cancer: unlocking the heterogeneity. J Ovarian Res 2018;11(1):1-12.

63. Choi S, Bakkenist CJ. Brd4 shields chromatin from ATM kinase signaling storms. Sci Signal. 2013 ;6(293):pe30. Available from: https://stke.scien cemag.org/lookup/doi/10.1126/scisignal.2004622.

64. Villar-Prados A, Wu SY, Court KA, Ma S, LaFargue C, Chowdhury MA, et al. Predicting novel therapies and targets: regulation of Notch 3 by the Bromodomain protein BRD4. Mol Cancer Ther 2019;18(2):421-436. Available from: http://mct.aacrjournals.org/lookup/doi/https://doi.org/ 10.1158/1535-7163.MCT-18-0365

65. Grimwood J, Gordon LA, Olsen A, Terry A, Schmutz J, Lamerdin J, et al. The DNA sequence and biology of human chromosome 19. Nature. 2004;428(6982):529-35 Available from: http://www.nature.com/artic les/nature02399.

66. Jones D, Lin D. Amplification of the NSD3-BRD4-CHD8 pathway in pelvic high-grade serous carcinomas of tubo-ovarian and endometrial origin. Mol Clin Oncol. 2017;19:301-7.

67. Yokoyama Y, Zhu H, Lee JH, Kossenkov A V., Wu SY, Wickramasinghe $\mathrm{JM}$, et al. BET inhibitors suppress ALDH activity by targeting ALDH1A1 super-enhancer in ovarian cancer. Cancer Res. 2016 ;76(21):6320-30. Available from: http://cancerres.aacrjournals.org/lookup/doi/10.1158/ 0008-5472.CAN-16-0854.

68. Zhang J, Dulak AM, Hattersley MM, Willis BS, Nikkilä J, Wang A, et al. BRD4 facilitates replication stress-induced DNA damage response. Oncogene. 2018;37(28):3763-77 Available from: http://www.nature. com/articles/s41388-018-0194-3.

69. Curtis $C$, et al. Comprehensive molecular portraits of human breast tumours. Nature. 2012;490(7418):61-70. Available from: http://www. nature.com/articles/nature11412.
70. Devaiah BN, Mu J, Akman B, Uppal S, Weissman JD, Cheng D, et al. MYC protein stability is negatively regulated by BRD4. Proc Natl Acad Sci U S A. 2020;117(24):13457-67.

71. Delmore JE, Issa GC, Lemieux ME, Rahl PB, Shi J, Jacobs HM, et al. BET Bromodomain inhibition as a therapeutic strategy to target c-Myc. Cell. 2011;146(6):904-17. Available from: https://linkinghub.elsevier.com/ retrieve/pii/S0092867411009433.

72. Bagratuni T, Mavrianou N, Gavalas NG, Tzannis K, Arapinis C, Liontos M, et al. JQ1 inhibits tumour growth in combination with cisplatin and suppresses JAK/STAT signalling pathway in ovarian cancer. Eur J Cancer. 2020;126:125-35. Available from: https://doi.org/10.1016/j.ejca.2019.11. 017.

73. Qiu H, Jackson AL, Kilgore JE, Zhong Y, Chan LLY, Gehrig PA, et al. JQ1 suppresses tumor growth through downregulating LDHA in ovarian cancer. Oncotarget. 2015;6(9):6915-30.

74. Gupta N, Xu Z, El-Sehemy A, Steed H, Fu Y. Notch3 induces epithelialmesenchymal transition and attenuates carboplatin-induced apoptosis in ovarian cancer cells. Gynecol Oncol 2013;130(1):200-6. Available from: http://dx.doi.org/10.1016/j.ygyno.2013.03.019.

75. Park JT, Li M, Nakayama K, Mao TL, Davidson B, Zhang Z, et al. Notch3 gene amplification in ovarian cancer. Cancer Res. 2006;66(12):6312-8.

76. Hu W, Liu T, Ivan C, Sun Y, Huang J, Mangala LS, et al. Notch3 pathway alterations in ovarian cancer. Cancer Res. 2014;74(12):3282-93.

77. Xu Y, Miao C, Jin C, Qiu C, Li Y, Sun X, et al. SUSD2 promotes cancer metastasis and confers cisplatin resistance in high grade serous ovarian cancer. Exp Cell Res. 2018;363(2):160-70. Available from: https://doi. org/10.1016/j.yexcr.2017.12.029.

78. Sheng Q, Liu X, Fleming E, Yuan K, Piao H, Chen J, et al. An activated ErbB3/NRG1 autocrine loop supports in vivo proliferation in ovarian Cancer cells. Cancer Cell 2010;17(3):298-310. Available from: http://dx. doi.org/10.1016/i.ccr.2009.12.047.

79. Pradeep S, Kim SW, Wu SY, Nishimura M, Chaluvally-Raghavan P, Miyake $T$, et al. Hematogenous metastasis of ovarian Cancer: rethinking mode of spread. Cancer Cell 2014;26(1):77-91. Available from: http://dx.doi. org/10.1016/j.ccr.2014.05.002.

80. Zheng H, Zhang M, Ma S, Yang W, Xie S, Wang Y, et al. Identification of the key genes associated with chemotherapy sensitivity in ovarian cancer patients. Cancer Med. 2020;9(14):5200-9.

81. Lu JJ, Abudukeyoumu A, Zhang X, Liu LB, Li MQ, Xie F. Heme oxygenase 1: a novel oncogene in multiple gynecological cancers. Int J Biol Sci. 2021;17(9):2252-61.

82. Li D, Hong X, Zhao F, Ci X, Zhang S. Targeting Nrf2 may reverse the drug resistance in ovarian cancer. Cancer Cell Int. 2021;21(1):1-10. Available from: https://doi.org/10.1186/s12935-021-01822-1.

83. Cho H, Kim K, Kim Y-B, Kim H, No JH. Expression patterns of Nrf2 and Keap1 in ovarian Cancer cells and their prognostic role in disease recurrence and patient survival. Int J Gynecol Cancer 2017;27(3):412-9. Available from: https://ijgc.bmj.com/lookup/doi/10.1097//GC.00000 00000000908.

84. Gorrini C, Baniasadi PS, Harris IS, Silvester J, Inoue S, Snow B, et al. BRCA1 interacts with Nrf2 to regulate antioxidant signaling and cell survival. J Exp Med. 2013;210(8):1529-44.

85. Maines MD, Kappas A. Enzymic oxidation of cobalt protoporphyrin IX: observations on the mechanism of heme oxygenase action. Biochem Int 1977;16(3):419-23. Available from: https://pubs.acs.org/doi/abs/10. 1021/bi00622a012.

86. Zhao Z, Xu Y, Lu J, Xue J, Liu P. High expression of HO-1 predicts poor prognosis of ovarian cancer patients and promotes proliferation and aggressiveness of ovarian cancer cells. Clin Transl Oncol. 2018;20(4):491-9.

87. Fuh K, Mullen M, Blachut B, Stover E, Konstantinopoulos P, Liu J, et al. Homologous recombination deficiency real-time clinical assays, ready or not? Gynecol Oncol. 2020;159(3):877-86. Available from: https://doi. org/10.1016/j.ygyno.2020.08.035.

88. McCormick A, Donoghue P, Dixon M, O'Sullivan R, O'Donnell RL, Murray $J$, et al. Ovarian cancers harbor defects in nonhomologous end joining resulting in resistance to rucaparib. Clin Cancer Res. 2017;23(8):2050-60.

89. Wong-Brown MW, van der Westhuizen A, Bowden NA. Targeting DNA Repair in ovarian Cancer treatment resistance. Clin Oncol. 2020;32(8):518-26. Available from: https://doi.org/10.1016/j.clon.2020. 03.005 . 
90. O'Connor MJ. Targeting the DNA damage response in Cancer. Mol Cell 2015;60(4):547-60. Available from: http://dx.doi.org/10.1016/j.molcel. 2015.10.040.

91. Zhang Y, Hunter T. Roles of Chk1 in cell biology and cancer therapy. Int J Cancer. 2014;134(5):1013-23 Available from: https://onlinelibrary.wiley. com/doi/10.1002/ijc.28226.

92. Meng E, Mitra A, Tripathi K, Finan MA, Scalici J, McClellan S, et al. ALDH1A1 maintains ovarian cancer stem cell-like properties by altered regulation of cell cycle checkpoint and DNA repair network signaling. PLoS One. 2014;9(9):e107142.

93. Clark DW, Palle K. Aldehyde dehydrogenases in cancer stem cells: potential as therapeutic targets. Ann Transl Med. 2016;4(24):1-8.

94. Liu L, Cai S, Han C, Banerjee A, Wu D, Cui T, et al. ALDH1A1 contributes to PARP inhibitor resistance via enhancing DNA repair in BRCA2 -/ovarian Cancer cells. Mol Cancer Ther 2020;19(1):199-210. Available from: http://mct.aacrjournals.org/lookup/doi/10.1158/1535-7163. MCT-19-0242.

95. Ji YJ, Shao Y, Zhang J, Zhang X, Qiang P. Bromodomain-containing protein 4 silencing by microRNA-765 produces anti-ovarian cancer cell activity. Aging (Albany NY). 2021;13(6):8214-27.

96. Tan DS, Agarwal R, Kaye SB. Mechanisms of transcoelomic metastasis in ovarian cancer. Lancet Oncol. 2006;7(11):925-34. Available from: http:// ovidsp.ovid.com/ovidweb.cgi?T $=J S \& P A G E=$ reference $\& D=$ emed7\& NEWS $=N \& A N=2006519275$.

97. Lengyel E. Ovarian cancer development and metastasis. Am J Pathol. 2010.

98. Zhou B, Xu H, Xia M, Sun C, Li N, Guo E, et al. Overexpressed miR-9 promotes tumor metastasis via targeting E-cadherin in serous ovarian cancer. Front Med. 2017;11(2):214-22.

99. Sui X, Jiao YN, Yang LH, Liu J. MiR-9 accelerates epithelial-mesenchymal transition of ovarian cancer cells via inhibiting e-cadherin. Eur Rev Med Pharmacol Sci. 2021;23(3):209-16.

100. Nieszporek A, Skrzypek K, Adamek G, Majka M. Molecular mechanisms of epithelial to mesenchymal transition in tumor metastasis. Acta Biochim Pol. 2019;66. Available from: https://ojs.ptbioch.edu.pl/index.php/ abp/article/view/2899.

101. Elloul S, Elstrand MB, Nesland JM, Tropé CG, Kvalheim G, Goldberg I, et al. Snail, slug, and smad-interacting protein 1 as novel parameters of disease aggressiveness in metastatic ovarian and breast carcinoma. Cancer. 2005;103(8):1631-43.

102. Wang L, Liu K, Jeng W, Chiang C, Chai C, Chiou S, et al. PCAF -mediated acetylation of ISX recruits BRD 4 to promote epithelial-mesenchymal transition. EMBO Rep. 2020;21(2):1-16.

103. Li X, Fu Y, Yang B, Guo E, Wu Y, Huang J, et al. BRD4 inhibition by AZD5153 promotes antitumor immunity via depolarizing M2 macrophages. Front Immunol. 2020;1 1(February):1-12.

104. Baratta MG, Schinzel AC, Zwang Y, Bandopadhayay P, Bowman-Colin C, Kutt J, et al. An in-tumor genetic screen reveals that the BET bromodomain protein, BRD4, is a potential therapeutic target in ovarian carcinoma. Proc Natl Acad Sci U S A. 2015;112(1):232-7.

105. Wilson AJ, Stubbs M, Liu P, Ruggeri B, Khabele D. The BET inhibitor INCB054329 reduces homologous recombination efficiency and augments PARP inhibitor activity in ovarian cancer. Gynecol Oncol. 2018;149(3):575-84. Available from: https://linkinghub.elsevier.com/ retrieve/pii/S0090825818302294.

106. Bauer K, Berger D, Zielinski CC, Valent P, Grunt TW. Hitting two oncogenic machineries in cancer cells: cooperative effects of the multi-kinase inhibitor ponatinib and the BET bromodomain blockers JQ1 or dBET1 on human carcinoma cells. Oncotarget. 2018:9(41):26491-506.

107. Filippakopoulos P, Qi J, Picaud S, Shen Y, Smith WB, Fedorov $\mathrm{O}$, et al. Selective inhibition of BET bromodomains. Nature. 2010;468(7327):1067-73.

108. Kurimchak AM, Shelton C, Herrera-Montavez C, Duncan KE, Chernoff J, Duncan JS. Intrinsic resistance to MEK inhibition through BET proteinmediated kinome reprogramming in NF1-deficient ovarian cancer. Mol Cancer Res. 2019;17(8):1721-34.

109. Jing Y, Zhang Z, Ma P, An S, Shen Y, Zhu L, et al. Concomitant BET and MAPK blockade for effective treatment of ovarian cancer. Oncotarget. 2016;7(3):2545-54.
110. Kurimchak AM, Shelton C, Duncan KE, Johnson KJ, Brown J, O'Brien S, et al. Resistance to BET Bromodomain inhibitors is mediated by Kinome reprogramming in ovarian Cancer. Cell Rep. 2016;16(5):1273-86.

111. Liu A, Fan D, Wang Y. The BET bromodomain inhibitor i-BET151 impairs ovarian cancer metastasis and improves antitumor immunity. Cell Tissue Res. 2018;374(3):577-85.

112. Momeny M, Eyvani H, Barghi F, Ghaffari SH, Javadikooshesh S, Jamadi $\mathrm{RH}$, et al. Inhibition of bromodomain and extraterminal domain reduces growth and invasive characteristics of chemoresistant ovarian carcinoma cells. Anti-Cancer Drugs. 2018;29(10):1011-20.

113. Zhang Z, Ma P, Jing Y, Yan Y, Cai MC, Zhang M, et al. BET bromodomain inhibition as a therapeutic strategy in ovarian cancer by downregulating foxm 1. Theranostics. 2016;6(2):219-30.

114. Carey P, Low E, Harper E, Stack MS. Metalloproteinases in ovarian cancer Int J Mol Sci. 2021;22(7):1-15.

115. Servidei T, Meco D, Martini M, Battaglia A, Granitto A, Buzzonetti A, et al. The bet inhibitor otx015 exhibits in vitro and in vivo antitumor activity in pediatric ependymoma stem cell models. Int J Mol Sci. 2021;22(4):1-19.

116. Maser T, Zagorski J, Kelly S, Ostrander A, Goodyke A, Nagulapally A, et al. The MDM2 inhibitor CGM097 combined with the BET inhibitor OTX015 induces cell death and inhibits tumor growth in models of neuroblastoma. Cancer Med. 2020;9(21):8144-58.

117. Sun C, Yin J, Fang Y, Chen J, Jeong KJ, Chen $X$, et al. BRD4 inhibition is synthetic lethal with PARP inhibitors through the induction of homologous recombination deficiency. Cancer Cell. 2018;33(3):401-16.e8. https://doi.org/10.1016/j.ccell.2018.01.019.

118. Karakashev S, Zhu H, Yokoyama Y, Zhao B, Fatkhutdinov N, Kossenkov $A V$, et al. BET bromodomain inhibition synergizes with PARP inhibitor in epithelial ovarian cancer. Cell Rep. 2017;21(12):3398-405. Available from: https://linkinghub.elsevier.com/retrieve/pii/S221112471731762X.

119. Fallahi P, Ferrari SM, Elia G, Ragusa F, Paparo SR, Camastra S, et al. Endocrine-metabolic effects of treatment with multikinase inhibitors. Eur J Endocrinol. 2021;184(1):R29-40.

120. Shorstova T, Su J, Zhao T, Dahabieh M, Leibovitch M, de Sa Tavares Russo M, et al. reprogramming of nucleotide metabolism mediates synergy between epigenetic therapy and MAP kinase inhibition. Mol Cancer Ther. 2021;20(1):64-75.

121. Al Bakir M, Gabra H. The molecular genetics of hereditary and sporadic ovarian cancer: implications for the future. Br Med Bull. 2014;112(1):57-69.

122. Chen S, Cavazza E, Barlier C, Salleron J, Filhine-Tresarrieu P, Gavoille C, et al. Beside P53 and PTEN: identification of molecular alterations of the RAS/MAPK and PI3K/AKT signaling pathways in high-grade serous ovarian carcinomas to determine potential novel therapeutic targets. Oncol Lett. 2016;12(5):3264-72.

123. Morel D, Almouzni G, Soria JC, Postel-Vinay S. Targeting chromatin defects in selected solid tumors based on oncogene addiction, synthetic lethality and epigenetic antagonism. Ann Oncol. 2017;28(2):25469. Available from: https://doi.org/10.1093/annonc/mdw552.

124. Piha-Paul SA, Sachdev JC, Barve M, LoRusso P, Szmulewitz R, Patel SP, et al. First-in-human study of mivebresib (ABBV-075), an oral paninhibitor of bromodomain and extra terminal proteins, in patients with relapsed/ refractory solid tumors. Clin Cancer Res. 2019;25(21):6309-19.

125. Piha-Paul SA, Hann CL, French CA, Cousin S, Braña I, Cassier PA, et al. Phase 1 study of molibresib (GSK525762), a bromodomain and extraterminal domain protein inhibitor, in NUT carcinoma and other solid tumors. JNCI Cancer Spectr. 2020;4(2):1-9.

126. Lewin J, Soria JC, Stathis A, Delord JP, Peters S, Awada A, et al. Phase Ib trial with birabresib, a small-molecule inhibitor of bromodomain and extraterminal proteins, in patients with selected advanced solid tumors. J Clin Oncol. 2018;36(30):3007-14.

127. Sun Y, Han J, Wang Z, Li X, Sun Y, Hu Z. Safety and efficacy of Bromodomain and extra-terminal inhibitors for the treatment of hematological malignancies and solid tumors: a systematic study of clinical Trials. Front Pharmacol. 2021;11(January):1-15.

128. Andrieu G, Belkina AC, Denis GV. Clinical trials for BET inhibitors run ahead of the science. Drug Discov Today Technol. 2016;19:45-50.

129. Duan Y, Guan Y, Qin W, Zhai X, Yu B, Liu H. Targeting Brd4 for cancer therapy: inhibitors and degraders. Medchemcomm. 2018;9(11):1779-802. 
130. Luan W, Pang Y, Li R, Wei X, Jiao X, Shi J, et al. Akt/mTOR-mediated autophagy confers resistance to bet inhibitor JQ1 in ovarian cancer. Onco Targets Ther. 2019;12:8063-74.

131. Sun Y, Zhang Z, Zhang K, Liu Y, Shen P, Cai M, et al. Epigenetic heterogeneity promotes acquired resistance to BET bromodomain inhibition in ovarian cancer. Am J Cancer Res. 2021;11(6):3021-38. Available from: http://www.ncbi.nlm.nih.gov/pubmed/34249442.

132. Zengerle $\mathrm{M}$, Chan $\mathrm{KH}$, Ciulli A. Selective small molecule induced degradation of the BET Bromodomain protein BRD4. ACS Chem Biol. 2015;10(8):1770-7.

133. Bauer K, Berghoff AS, Preusser M, Heller G, Zielinski CC, Valent P, Grunt TW. Degradation of BRD4 - a promising treatment approach not only for hematologic but also for solid cancer. Cell Rep. 2021;11(2):530-45. http://www.ncbi.nlm.nih.gov/pubmed/33575085.

134. Bolden J, Tasdemir N, Dow L, Van EJH, Wilkinson JE, Zhao Z, et al. Abstract LB-40: Inducible in vivo silencing of Brd4 identifies potential toxicities of sustained BET protein inhibition. Am J Can Res. 2014;8(6):LB-40.

135. Andrieu GP, Denis G V. BET proteins exhibit transcriptional and functional opposition in the epithelial-to-mesenchymal transition. Mol Cancer Res. 2018;16(4):580-6. Available from: http://mcr.aacrjournals. org/lookup/doi/10.1158/1541-7786.MCR-17-0568.

136. Lu L, Chen Z, Lin X, Tian L, Su Q, An P, et al. Inhibition of BRD4 suppresses the malignancy of breast cancer cells via regulation of snail. Cell Death Differ 2020;27(1):255-68. Available from: http://dx.doi.org/10. 1038/s41418-019-0353-2.

\section{Publisher's Note}

Springer Nature remains neutral with regard to jurisdictional claims in published maps and institutional affiliations.
Ready to submit your research? Choose BMC and benefit from:

- fast, convenient online submission

- thorough peer review by experienced researchers in your field

- rapid publication on acceptance

- support for research data, including large and complex data types

- gold Open Access which fosters wider collaboration and increased citations

- maximum visibility for your research: over 100M website views per year

At BMC, research is always in progress.

Learn more biomedcentral.com/submissions 